\title{
Documentation Practice and Associated Factors among Nurses in Harari Regional State and Dire Dawa Administration Governmental Hospitals, Eastern Ethiopia
}

Takla Tamir Melkie ( $\sim$ taklat12@gmail.com )

Research article

Keywords: Documentation Practice, Nursing care standards, Associated factors

Posted Date: July 8th, 2020

DOI: https://doi.org/10.21203/rs.3.rs-38278/v1

License: (c) (1) This work is licensed under a Creative Commons Attribution 4.0 International License. Read Full License 


\section{Documentation Practice and Associated Factors among Nurses in Harari Regional State and Dire Dawa Administration Governmental Hospitals, Eastern Ethiopia.}

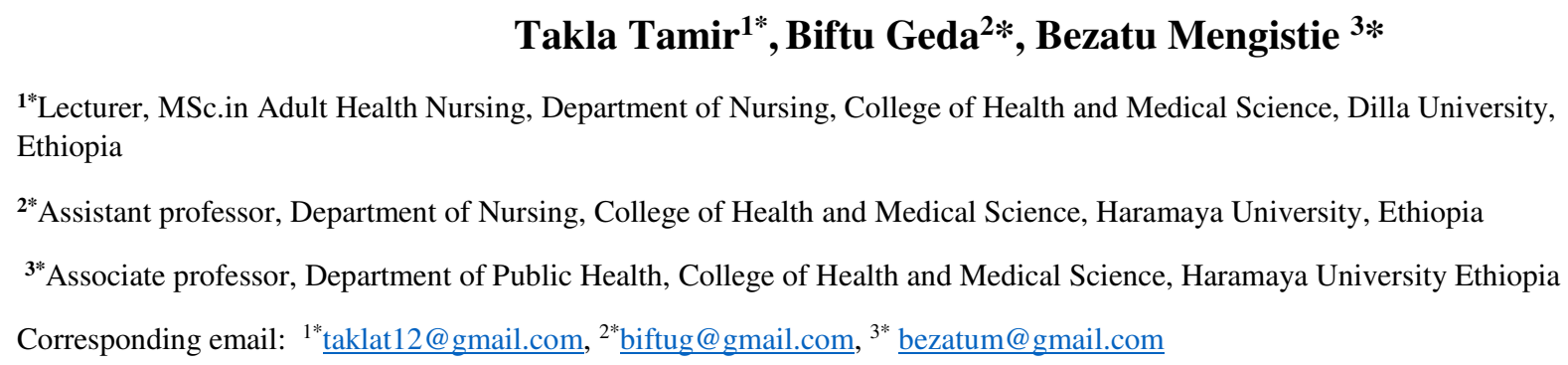

ABSTRACT

Background: Nursing documentation is an integral and vital professional nursing practice, deals the process of recording nursing activities concerned with the care given to individual clients to assure continual effective, safe, qualified, evidence-based and individualized care. Despite of this, in Ethiopia there is a paucity of information on nursing documentation practice and its associated factors due to limited studies with methodological limitations. So this study aimed to assess documentation practice and identify its associated factors among nurses in six Governmental Hospitals of Harari Regional State and Dire Dawa Administration, Eastern Ethiopia. Methods: Institutional based cross-sectional study was conducted among 430 nurses and 421 medical records. Simple random sampling was employed for the selection of nurses and charts after the total sample size had allocated proportionally for each hospital. Data were collected by using selfadministered questionnaire and review of records; entered and analyzed by using Epi data version 3.1 and statistical package for social sciences version 20.0 respectively. Logistic regression was used to identify the associated factors. Result: In this study, $47.5 \%$ of nurses were found to have good nursing documentation practice whereas good nursing documentation was found to practiced on $38.5 \%$ of medical records. Age, attitude, in-service training, nurse to patient ratio, availability of motivation and familiarity with standards of nursing documentation were found to had statistically significant positive association with documentation practice with AOR and 95\%CI of 3.54 (1.170-10.8), 5.66 (3.17- 10.11), 2.53(1.477-4.35), 2.24(1.24-4.047), 4.60 (2.721-7.76) and 1.98 (1.137-3.44) respectively. Conclusion: Documentation was practiced poorly due to the identified factors. Therefore, it is better to put further effort towards improving documentation practice through providing training on standards of documentation and enhancing favorable attitude of nurses towards documentation by motivating them for their documentation activities. Key words: Documentation Practice, Nursing care standards, Associated factors 


\section{INTRODUCTION}

Nursing documentation is the process of recording $(1,2)$ and keeping evidence to have an account of what happened and when it happened $(1,3)$. It is an integral, vital and important part of professional nursing practice (4) with the primary purpose of communicating patient information to the health care team (5).

Nursing documentation promotes effective communication, ensures early detection of problems, quality, continuity, individuality as well as complete client care and patient safety that ultimately increases the quality of life through which it determines the standard of care rendered by nurses $(1,2,6)$. It also enhances professional autonomy, critical thinking skills of nurses, development of professional knowledge and nursing education. It is a legal witness for nurses' act $(7,8)$. Its contribution to the research environment, credentialing, reimbursement and auditing clinical services is invaluable (9) which helps the profession to be advanced and visible $(10,11)$.

Quality of patient care depends on the caregiver's ability to have accurate, timely and effective exchange of oral or written information, ideas and feelings with patients and colleagues. $(12,13)$. Even though there is no way to prove care was provided without completed documentation (2, 14) as many studies indicated globally most of the nurse's actions are either not documented or not properly documented $(2,5,15,16)$. In Africa as well in Ethiopia, the act of nursing documentation remains challenging due to lack of training, resources, comprehensive nursing education (CNE), time, high nurse to patient ratio, poor knowledge and attitude $(1,5,17)$.

Nurses play an important role in the care of patients and what they put into writing determines the standard and quality of care rendered to the patient (2). Documentation is the tip of the iceberg of patient care issues that could expose caregivers to medico-legal suits and other forms of disciplinary action (18). So letdown to document appropriately creates a great problem when it comes to the evaluation of client care (2) and is a key factor in miscommunication among nurses and physicians, delayed, repeated or omitted and fragmented care that will cause preventable medical errors which may potentially affect patient outcomes (1). Ineffective documentation cause clinical mishaps and crucial issue in many malpractice cases (19) and continues to be cited as a major cause of adverse events for patients $(20,21)$. Poor nursing documentation can place patients, staffs as well as organizations at considerable risk of physical and legal harm (22) 
As per review of available literature, there is a paucity of information about documentation practice and its associated factors due few studies which were limited only in one hospital, done with small sample size and more over measure the practice through self-reported questions. Therefore, this study aimed to fill those gaps and to provide relatively strong and additional baseline evidence that help to plan intervention programs for poor nursing documentation practice and to avert its effects at different leveles.

\section{METHODS AND MATERIALS}

\section{Study design and seting}

Institutional based quantitative cross-sectional study was conducted from March 15-25/2019 in Governmental Hospitals of Harari Regional State and Dire Dawa Administration located in the in the eastern part of the country at a distance of 523 and $515 \mathrm{Kms}$ respectively from Addis Ababa, the capital city of Ethiopia. There were 101 governmental health care facilities of which 6 were hospitals and 2282 health care workers of which $44.3 \%$ of them were nurse by their profession.

\section{Population}

All nurses working in Harari regional State and Dire Dawa Administration Governmental Hospitals were source and study populations.

\section{Eligibility Criteria}

Nurses involved in direct patient care with work experience of at least 6 months were included.

\section{Sample size and sampling procedure}

Sample size was determined by using Epinpho Version 7 for the two objectives separately. So the minimum adequte but the maximum calculated sample size was 442 after adding $10 \%$ non response rate. Hading the determined sample size proportional allocation was done for each hospital followed by simple random sampling to select each participant using sampling frame from Human Resource. The same sample size and sampling technique was applied to select charts with sampling frame of list of a one month medical registration numbers nearest to the study period from inpatient department and again proportional allocation was done for each ward found in the hospital to increase the representativeness.

\section{Study variables}


After reviewing existing litrature, all the study variables had summerized by the coceptual framework in the figure below (Figure 1).

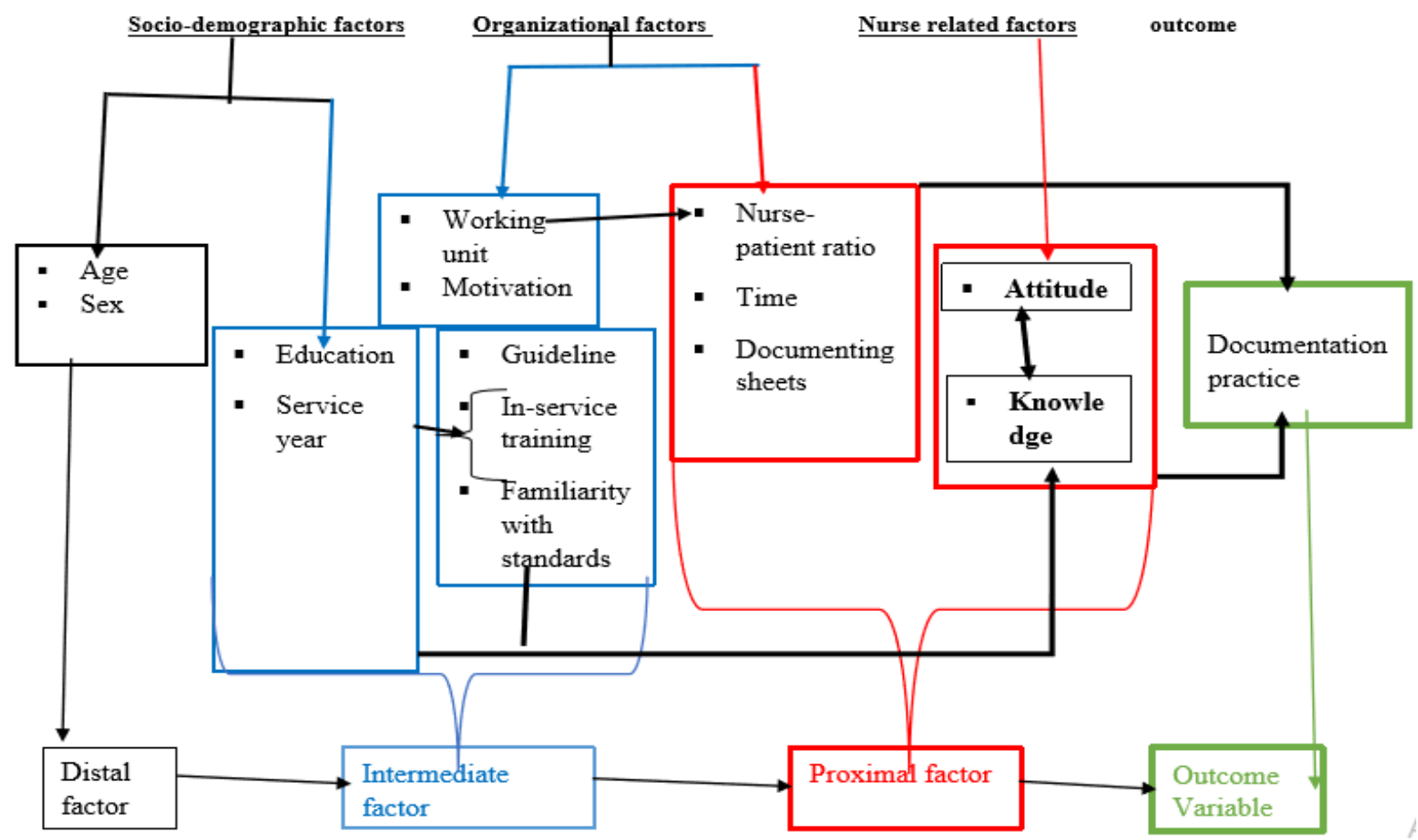

Figure1: A conceptual framework of Documentation Practice and Associated Factors among Nurses in Harari Region and Dire Dawa Administration Governmental Hospitals, Eastern Ethiopia 2019 adopted and modified from (1).

\section{Data Collection Tool}

Structured self-administered English version questionnaire adapted from reviewed literature (1, 17) was used to collect data regarding the socio-demographic characteristics of the nurses, organizational factors, knowledge and attitude of nurses toward nursing documentation and selfreported documentation practice. Structured English version standard checklist adapted from reviewed literature and guidelines $(1,12,13,23)$ was used to review medical records separately from nurses and to collect the data regarding to nursing documentation practice objectively.

\section{Operational Definitions}

Good practice: A score of $\geq$ the median score for practice questions otherwise poor.Good knowledge: A score of $\geq$ the median score for knowledge questions otherwise poor (1). 
Favorable atitude: $\geq$ the median score for attitude questions otherwise Unfavorable (1).Adequate nurse to patient ratio: if a nurse serves for $\leq 2$ patient in ICU or $\leq 6$ patients in other than ICU inpatient otherwise Inadequate (24).

\section{Data quality control}

Properly aimed data collection tool was prepared and tested on five percent of the total sample at the questionnaire level. Data collectors and supervisors recruited were not the employee of the study hospitals to minimize bias and adequate training was given. On each data collection day, some percent of the collected data were examined by the principal investigator and any forwarded problem had got an immediate solution at the data collection stage.

After the data had been collected, were checked for completeness, accuracy, clarity and consistency by the principal investigator and supervisors before data entry into software and each questionnaire which were decided to be entered to the software for analysis were properly coded. Data double entry into Epi data version 3.1 was done. Consistency of data entry was validated. After all, data screening was made through running descriptive statistics and data cleaning measures were taken accordingly before data analysis at the data processing stage.

\section{Method of Data Processing and Analysis}

Data were exported to SPSS Version-20 software for analysis. Variables were computed and recoded through transform function of SPSS. Descriptive analysis was done to compute proportions and summary measures. Summery measures, tables and figures were used to present the processed information. Attitude towards nursing documentation was computed from summing up all relevant 10 five scale likert attitude items, respondents who scored median and above were labeled as having a favorable attitude. Knowledge about nursing documentation was computed from summing up all relevant 09 multiple choice items, respondents who scored median and above were labeled as having good knowledge. Practice of nursing documentation was computed from summing up all relevant 09 likert practice items for self-reported and 12 likert practice checklist items for chart review, respondents or records who scored median and above were labeled as having good nursing documentation practice. Self-reported documentation practice was used to identify associated factors. 
Bivariate analysis, crude odds ratio with $95 \%$ CI, was estimated to see the crude association between each independent variables with the dependent variable. All variables with $\mathrm{P} \leq 0.25$ at 95\% confidence level during the bivariate analysis were a candidate for multivariate analysis. Multi co-linearity test was carried out to see the linear correlation among independent variables by using standard error. Standard error $>2$ was considered as suggestive of existence of multi colinearity. Hosmer -Lemeshow goodness- of- fit was done to check model fitness. Adjusted odds ratio with $95 \%$ CI were estimated during multivariate analysis to identify factors associated with documentation practice. Independent variables at the level of statistical significance $\mathrm{P}<0.05$ which does not include null value in the $95 \%$ CI were declared as significant.

\section{RESULT}

\section{Socio-Demographic Characteristics}

Four hundred thirty nurses participated in the study giving a response rate of $97.3 \%$.The age of the study participants ranged from 21 to 58 years with a median age of 29 years. Majority of the respondents were males $(54.4 \%)$. Nearly eighty percent of them $(79.3 \%)$ were found to had BSc degree and above in nursing. (Table 1).

Table 1: Socio-demographic characteristics of nurses in Governmental Hospitals of Harari Regional State and Dire Dawa Administration, Eastern Ethiopia, 2019(n=430)

\begin{tabular}{|clcc|}
\hline \multicolumn{2}{c}{ Variables } & Frequency (n) & Percent (\%) \\
\hline Age group (in years) & $21-25$ & 93 & 21.6 \\
& $26-30$ & 152 & 35.3 \\
& $31-35$ & 96 & 22.3 \\
& Above 35 & 89 & 20.8 \\
\hline Sex & Male & 234 & 54.4 \\
& Female & 196 & 45.6 \\
\hline Educational level & College diploma & 89 & 20.7 \\
& BSc and above & 341 & 79.3 \\
\hline Work experience(in years) & 5 and less & 224 & 52.1 \\
& 6-10 & 117 & 27.2 \\
& 11 and above & 89 & 20.7 \\
\hline Working unit (current) & Medical ward & 106 & 24.7 \\
& Surgical ward & 92 & 21.4 \\
& Pediatrics ward & 38 & 8.8 \\
& OR & 34 & 7.9 \\
& ICU & 39 & 9.1 \\
& EOPD & 35 & 8.1 \\
& Regular OPD & 86 & 20 \\
\hline
\end{tabular}




\section{Organizational factors}

Out of four hundred thirty participant nurses, $49 \%$ attended in-service training on standards of nursing documentation. Only $47.9 \%$ and $59.8 \%$ of respondents easily got nursing documentation standard guideline and nursing documenting sheets respectively in their working unit. Nearly twothird $(66 \%)$ of them reported that they are familiar with operational standards of nursing documentation. Fifty three percent (53\%) of respondents were motivated by their supervisors for their documentation activities and $68.8 \%$ of respondents reported that they have enough time to document their nursing activities after the care they provided (Table 2).

Table 2: Frequency and percentage distribution of organizational factors among nurses in Governmental Hospitals of Harari Regional State and Dire Dawa Administration, Eastern Ethiopia, 2019 (n=430)

\begin{tabular}{|cccc|}
\hline Variables & & Frequency & Percentage \\
\hline Training attended & Yes & 211 & 49.1 \\
& No & 219 & 50.9 \\
\hline Average No of patients cared by a nurse & 5 and less & 153 & 35.6 \\
per shift & $6-10$ & 161 & 37.4 \\
& Above 10 & 116 & 27.0 \\
\hline Guideline availability & Yes & 206 & 47.9 \\
& No & 224 & 52.1 \\
\hline Familiarity with standards & Familiar & 284 & 66 \\
& Not familiar & 146 & 34 \\
\hline Documenting sheets & Adequate & 257 & 59.8 \\
& Inadequate & 173 & 40.2 \\
\hline Motivation from supervisors & Available & 228 & 53 \\
& Not available & 202 & 47 \\
\hline Time adequacy & Yes & 296 & 68.8 \\
& No & 134 & 31.2 \\
\hline
\end{tabular}

Knowledge and attitude of nurses towards nursing documentation

Out of the total study participants 50\%, CI (45\% - 55\%) of them had favorable attitude and 51.6\%, 95\% CI (46.7\% - 56.5\%) of them had good knowledge about nursing documentation (Fig.2). 


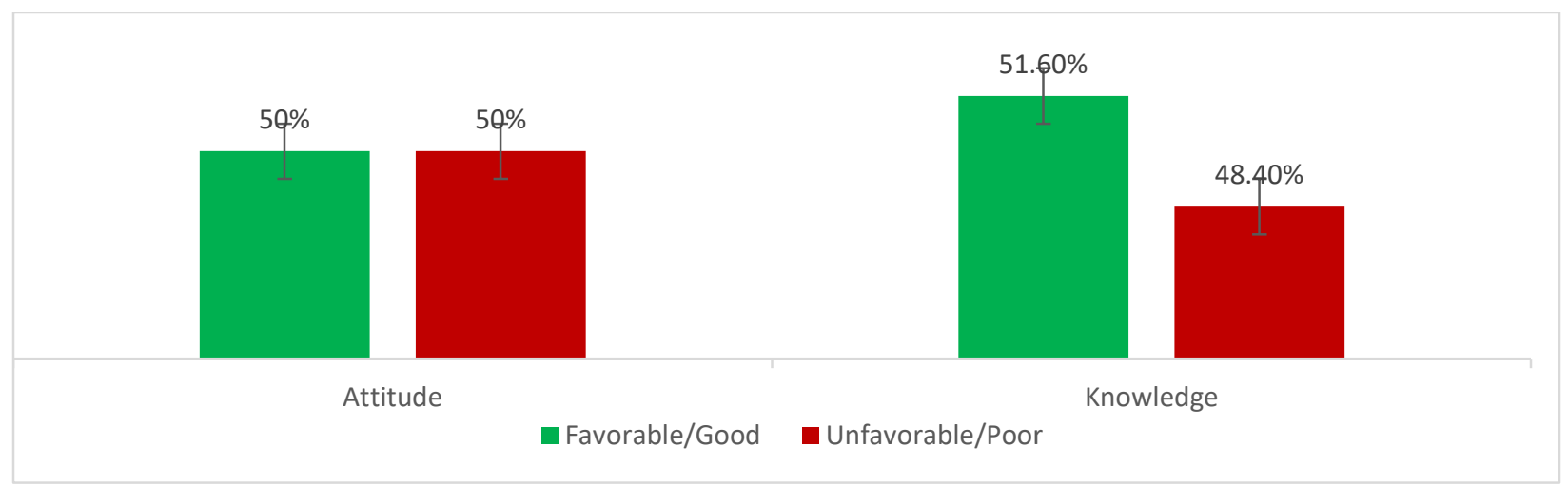

Figure 2: Graphic representation of categorized Attitude and knowledge of nurses towards nursing documentation in Governmental Hospitals of Harari Regional State and Dire Dawa City Administration, Eastern Ethiopia, 2019(n=430).

\section{Documentation practice}

Out of 430 participants $47.9 \%(n=206) ; 95 \% \mathrm{CI}(43.2 \%-52.6 \%)$ of respondents were found to had good documentation practice whereas out of 421 reviewed medical records good nursing documentation was found to practiced on $38.5 \%(n=162,95 \%$ CI (34\%-43.2\%) of them (Fig. 3).
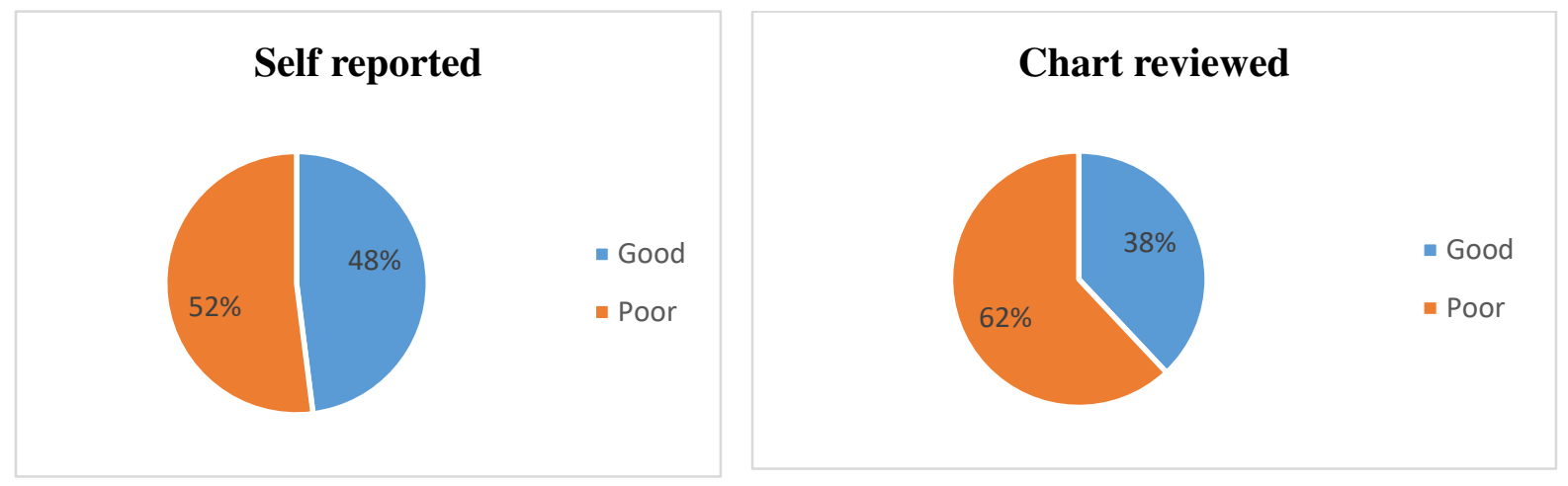

Figure 3: Categorized self-reported and chart reviewed documentation practices among nurses in Governmental Hospitals of Harari Regional State and Dire Dawa Administration, Eastern Ethiopia ( $\mathrm{n}=430$ and $n=421$ respectively ).

\section{Factors associated with documentation practice}

Age above 35, AOR 3.54, nursing standard training on nursing documentation 2.53, adequate nurse to patient ratio AOR 2.24, familiarity with operational standards of nursing documentation AOR 1.98, motivation from supervisors AOR 4.60 and favorable attitude towards nursing documentation AOR 5.66 were positively and independently associated with nursing documentation practice (Table 3). 
Table 3: Factors associated with documentation practice among nurses in Governmental Hospitals of Harari Region and Dire Dawa Administration, Eastern Ethiopia, 2019 ( $n=430)$

\begin{tabular}{|c|c|c|c|c|c|c|}
\hline \multirow[t]{2}{*}{ Variable } & & \multicolumn{2}{|c|}{ Documentation practice } & \multicolumn{2}{|c|}{$\begin{array}{l}\text { Bivariate logistic } \\
\text { regression }\end{array}$} & \multirow{2}{*}{$\begin{array}{l}\text { Multivariate logistic } \\
\text { regression } \\
\qquad \operatorname{AOR}(95 \% \mathrm{CI})\end{array}$} \\
\hline & & $\begin{array}{l}\text { Poor } \\
\mathrm{N}\end{array}$ & $\begin{array}{l}\text { Good } \\
\mathrm{N}\end{array}$ & COR & p-value & \\
\hline \multirow{4}{*}{ Age } & $21-25$ & 67 & 31 & 1 & & 1 \\
\hline & $26-30$ & 83 & 69 & 1.80 & .031 & $1.22(.597,2.491)$ \\
\hline & $31-35$ & 39 & 36 & 1.99 & .029 & $1.18(.448,3108)$ \\
\hline & Above 35 & 35 & 70 & 4.32 & $<.0001$ & 3.54(1.170,10.8)* \\
\hline \multirow[t]{2}{*}{ Sex } & Male & 123 & 111 & 1 & & \\
\hline & Female & 101 & 95 & 1.04 & .831 & \\
\hline \multirow[b]{2}{*}{ Education } & Diploma & 51 & 38 & 1 & & \\
\hline & $\geq \mathrm{MSc}$ & 173 & 168 & 1.30 & .270 & \\
\hline \multirow{4}{*}{$\begin{array}{l}\text { Working } \\
\text { unit }\end{array}$} & Out patient & 67 & 54 & 1 & & 1 \\
\hline & MW & 47 & 59 & 1.56 & .098 & $1.01(.472 .2 .145)$ \\
\hline & SW & 48 & 44 & 1.14 & .643 & $.592(.267,1.315)$ \\
\hline & Others & 62 & 49 & .981 & .941 & $.547(.258 .1 .163)$ \\
\hline \multirow[t]{3}{*}{ Service year } & $<=5$ & 142 & 82 & 1 & & 1 \\
\hline & $6-10$ & 52 & 65 & 2.165 & .001 & $1.60(.783,3.254)$ \\
\hline & Above10 & 30 & 59 & 3.406 & $<.0001$ & $1.58(.587,4.242)$ \\
\hline \multirow[t]{2}{*}{ Guideline } & No & 141 & 83 & 1 & & 1 \\
\hline & yes & 83 & 123 & 2.52 & $<.0001$ & $1.43(.89,2.395)$ \\
\hline \multirow{2}{*}{$\begin{array}{l}\text { Familiarity } \\
\text { with } \\
\text { standard }\end{array}$} & unfamiliar & 104 & 42 & 1 & & 1 \\
\hline & Familiar & 120 & 164 & 3.384 & $<.0001$ & $1.98(1.137,3.44)^{*}$ \\
\hline \multirow{2}{*}{$\begin{array}{l}\text { documentin } \\
\text { g sheet }\end{array}$} & Inadequate & 98 & 75 & 1 & & 1 \\
\hline & Adequate & 126 & 131 & 1.359 & .121 & $1.37(.810,2.315)$ \\
\hline \multirow{2}{*}{ Motivation } & No & 148 & 54 & 1 & & 1 \\
\hline & Yes & 76 & 152 & 5.481 & $<.0001$ & $4.60(2.721,7.76)^{* * *}$ \\
\hline \multirow{2}{*}{$\begin{array}{l}\text { Time } \\
\text { adequacy }\end{array}$} & No & 90 & 44 & 1 & & 1 \\
\hline & Yes & 134 & 162 & 2.473 & $<.0001$ & $1.69(.951,2.995)$ \\
\hline \multirow[t]{2}{*}{ Training } & No & 148 & 71 & 1 & & 1 \\
\hline & Yes & 76 & 135 & 3.703 & $<.0001$ & $2.53(1.477,4.35)^{* *}$ \\
\hline \multirow{2}{*}{$\begin{array}{l}\text { Nurse to } \\
\text { patient ratio }\end{array}$} & Inadequate & 150 & 105 & 1 & & 1 \\
\hline & Adequate & 74 & 101 & 1.950 & .001 & $2.24(1.24,4.047) * *$ \\
\hline \multirow[t]{2}{*}{ Attitude } & Unfavorable & 157 & 58 & 1 & & 1 \\
\hline & Favorable & 67 & 148 & 5.979 & $<.0001$ & $5.66(3.17,10.11) * * *$ \\
\hline \multirow[t]{2}{*}{ Knowledge } & Poor & 128 & 80 & 1 & & 1 \\
\hline & Good & 96 & 126 & 2.100 & $<.0001$ & $.747(.420,1.327)$ \\
\hline
\end{tabular}

$$
*(\mathrm{p}<0.05), * *(\mathrm{p}<0.01), * * *(\mathrm{p}<0.001)
$$




\section{DISCUSSION}

This study revealed that documentation practice was poor through both self-reported question and record review. Self-reported documentation practice was supported by the chart reviewed documentation practice but it was higher than the chart reviewed documentation practice. This discrepancy might be due to social desirability bias in the self-reported documentation practice.

For this study, record reviewed documentation practice is reported as the level of documentation practice which is almost similar with the finding of the study conducted in Gondar (1). The finding of this study was lower than the finding of the studies conducted in Jamaica (25), Nigeria (2), Ghana (18) and Jimma (17). The possible reason for this variation might be the tool utilized to determine the practice level of documentation $(2,17)$ self-administered questionnaire was used in those studies but medical record review for this study and this might be the fact that self-reported documentation practice may be overestimated due to social desirability bias. But this finding was higher than the finding of the studies conducted in Iran (26), Europe (27) and Canada (28). This discrepancy might be due to the ward type included in the study (26), the units included in the previous study were only medical-surgical wards and the workload was high in medical-surgical wards in teaching hospitals of Iran that may lesser nurses' documentation practice. The other possible reason for this discrepancy might also be due to area coverage difference (27) the study conducted in Europe covers large scale area but this study covers a small area. Even the type of study conducted may have its role on this discrepancy (28) the study conducted in Canada was prospective observational but retrospective review records in this study.

For this study, self-reported documentation practice was used to identify factors associated with documentation practice among nurses. Favorable attitude towards nursing documentation was positively associated with documentation practice This finding is in line with the finding of the study conducted in Iraq (22), Iran (Tabriz) (9), Nigeria (10) and Gondar (1). This might be due to that favorable attitude towards nursing documentation may be the strong and baseline internal motive of nurses to practice documentation.

Attaining standard training on nursing documentation was positively associated. This finding is comparable with the finding of the study conducted in Ghana (18), Uganda (5) and Gondar (1). This might be due to training may increase their familiarity with operational standards of 
documentation, may enhance their attitude towards nursing documentation and may also add their value of documenting what they have done.

Familiarity with operational standards of nursing documentation was significantly and positively associated. This finding is consistent with the finding of the study conducted in Jimma (17). This might be due to that familiarity with operational standards of nursing documentation may make tasks of documentation easy, fast and interesting for nurses.

Nurses motivated by their supervisors for their documentation activities were more likely to practice documentation when compared to nurses who were not motivated. Similarly, this evidence is in line with the finding of the study conducted in Jimma (17). This might be due to motivation may enhance nurses favorable attitude towards nursing documentation and initiate them to document their activity.

Adequate nurse to patient ratio was positively associated with nursing documentation practice. This finding is consistent with the finding of the study conducted in Western Jamaica (25), Eastern Ghana (18) and Gondar (1). This might be due to that adequate nurse to patient ratio may decrease workload and increase time to document their activity which makes documentation practice to be more likely.

Also in this study age had positively significant association with nursing documentation practice. This finding is comparable with the finding of the study conducted in Iraq, Al Najaf Governorate (8). This might be due to that most aged nurses were shown to have long service year as seen from crosstab, so their exposure to training may increase and this will make them familiar with operational standards of documentation. Again as their age increases, they may appreciate different multi-aspect advantages of documentation that will enhance their favorable attitude towards documentation which will achieve their documentation practice.

\section{Conclusion}

Documentation practice among nurses was poor. Attitude towards nursing documentation, Inservice training on standards of nursing documentation, familiarity with operational standards of nursing documentation, availability of motivation from supervisors, nurse to patient ratio and age of nurses had a statistically significant positive association with self-reported documentation practice. Therefore this study concludes that nursing documentation still remains a challenge. So 
it is better to put further effort towards improving documentation practice through providing training on standards of documentation and enhancing favorable attitude of nurses towards documentation by motivating them for their documentation activities.

\section{Declarations}

\section{Ethics approval and consent to participate}

Ethical clearance was obtained from Haramaya University, College of Health and Medical Sciences, Institute Health Research Ethics Review Committee. Permission letter and explanation about the aims, benefits and risks of the study was provided. So approval was obtained from the participating hospitals. Informed, voluntary, written and signed consent was obtained from each respondent. Confidentiality was maintained at all levels of the study through the anonymous data collection. Twelve BSc nurse data collectors and two MSc nurse supervisors were employed, trained and did the data collection activities with the principal investigators close supervision.

\section{Consent for publication (not applicable)}

\section{Availability of data and materials}

The datasets used and/or analyzed during the current study will not be shared in order to protect the participants' identities but are available from the corresponding author on reasonable request.

\section{Conflict of interest}

The authors declare that they have no competing interests

\section{Funding}

This research work was part of partial fulfilment for Master of Science in Adult Health Nursing and was funded by Dilla University through postgraduate students' research fund.

\section{Author's contribution}

TT conceived and designed the study and performed analysis and interpretation of data and manuscript preparation. BG and BM advised, supervised and guide the research process and gave constructive comments at each stage. All authors read and approved the final manuscript.

\section{Acknowledgement}

The authors would like to thank Dilla University, MOE, Haramaya University, all study participants, data collectors and supervisors. 


\section{References}

1. Mihiretu K, Yesuf E, Desalegn TZ. Nursing care documentation practice: The unfinished task of nursing care in the University of Gondar Hospital. Informatics for Health and Social Care. $2017 ; 42$

(3):290-302.

2. Taiye HB. Knowledge and Practice of Documentation among Nurses in Ahmadu Bello University Teaching Hospital (Abuth) Zaria, Kaduna State. 2015;4(6):01-6.

3. Li D. The Relationship between Nursing Documentation and Incidence of Pressure Ulcers in Intensive Care Units. Open Access Dissertations 1131 https://scholarlyrepositorymiamiedu/oa_dissertations/1131. 2013.

4. Okaisu EM, Kalikwani F, Wanyana G, Coetzee M. Improving the quality of nursing documentation: An action research project. Curationis. 2014;38(1):1-11.

5. Nakate G, Dahl D, Drake KB, Petrucka P. Knowledge and attitudes of select ugandan nurses towards documentation of patient care. African Journal of Nursing and Midwifery. 2015;2(1):056-65.

6. Wang N, Hailey D, Yu P. Quality of nursing documentation and approaches to its evaluation: a mixed-method systematic review. Journal of Advanced Nursing. 2011;67(9): 185875

7. Hameed RY, Allo RR. Assessment Of Nurses' Knowledge About Nursing Documentation. Kufa Journal for Nursing Sciences. 2014;4(1):1-9.

8. Jebur HG, Mohammed W. Evaluation of Nursing Staffs' Documentation Standard Related to Nursing Procedures at Medical Wards in Al-Najaf Al-Ashraf Governorate. Kufa Journal for Nursing Sciences. 2017;6(3):1-11.

9. Mohajjel AA, Lak DS, Rahmani A, Hassankhani H, Ahmadizadeh A. Survey of Knowledge, Attitude and Performance of Nursing Students towards Nursing Documentation. European Journal of Scientific Research. 2012; 80(2 ):191-8.

10. Dike FM, Onasoga OA, Njoku E. Documentation in labour among midwives in Madonna university teaching hospital elele, rivers state, Nigeria. Int J Reprod Contracept Obstet Gynecol 2015;4:1404-9.

11. Kerkina B, Lennox S, Patterson J. making midwifery work visible: multiple purpose of documentation. Elsevie/women and birth. 2017;31(2018):232-9.

12. FMOH. Fedral Ministry of Health, Nursing care practice standards communication in nursing . Addis Ababa, Ethiopia 2011 [Available from: https://www.medbox.org/nursing-carepractice-standards-reference-manual-for-nurses-and-healthcare.

13. FMOH. Fedral Ministry of Health, Ethiopian Hospital Reform Implementation Guidelines 2010 [Available from: https://www.scribd.com/document/358431689/Ethiopian-HospitalReform-Implementation-Guideline-PDF.

14. Mutshatshi TE, Mothiba TM, Mamogobo PM, Mbombi MO. Record-keeping: Challenges experienced by nurses in selected public hospitals. Curationis. 2018;41(1):1931-7. 
15. Jasemi M., Zamanzadeh V, Rahmani A., Mohajjel A., Alsadathoseini F. Nurses' Knowledge and Practice Regarding Nursing Documentation at Tabriz Teaching Hospitals. Thrita Journal of Medical Sciences. 2012;1(4):133-8.

16. Suhita BM, Sutrisno J, DewiK P. Factors Influencing Nurses in Implementing Documentation of Nursing at Muhammadiyah Hospital, Kediri City. Institute of Health Science "Surya Mitra Husada" Kediri, Indonesia. 2017;1(4):301-7.

17. Gizaw AB., Yimamreta E., SA. M. Documentation Practice and Associated factors among Nurses Working in Jimma University Medical Center, Jimma Town, South West Ethiopia. Advance Research Journal of Multidisciplinary Discoveries. 2018;30(10):54-61.

18. Asamanal JA., Amenorpe D., Babanawo, Ofei AMA. Nursing documentation of inpatient care in eastern Ghana. British Journal of Nursing. 2014;23(1):48-55.

19. DeLaune SC, Ladner PK. Fundamentals of nursing. 2nd ed2002.

20. Machudo SY, Mohidin S. Nursing Documentation Study at Teaching Hospital in KSA. Nursing and Health 2015 3(1):1-6.

21. Tower M, Chaboyer W, Green Q, Dyer K, Wallis M. Registered nurses' decision-making regarding documentation in patients' progress notes

Journal of clinical Nursing. 2012;21:2917-29.

22. Blair W, Smith B. Nursing documentation: frameworks and barriers. Contemporary nurse. 2012;41(2):160-8.

23. PAANS W., SERMEUS W., NIEWEG R.M.B., C.P. VDS. D-Catch instrument: development and psychometric testing of a measurement instrument for nursing documentation in hospitals. Journal of Advanced Nursing 2010;66(6):1388-400.

24. FMOH. Fedral Ministry of Health, Ethiopian Hospital Reform Implementation Guidelines 2012 [Available from: http://www.who.int/bulletin/online_first/BLT.14.151399.pdf.

25. Blake-Mowatt C., Lindo JLM., Bennett J. Evaluation of registered nurses' knowledge and practice of documentation at a Jamaican hospital. International Nursing Review. 2013;60:328-34

26. Aghdam ARM., Jasemi M., Rahmani A., V. Z. Quality of nursing documents in medicalsurgical wards of teaching hospitals related to Tabriz University of Medical Sciences. Iranian Journal of Nursing and Midwifery Research. 2009;14(2):45-50.

27. Ausserhofer D., Zander B., Busse R., Schubert M, De GS., Marie Rea, et al. Prevalence, patterns and predictors of nursing care left undone in European hospitals: results from the multicountry cross-sectional RN4CAST study. BMJ Qual Saf. 2014; 23(2):126-35.

28. Voyer P., McCusker J., Martin G., Monette J., Champoux N., Ciampi A., et al. Nursing documentation in long-term care settings:New empiricalevidence demands changes be made. Clinical nursing research. 2014 23(4):442-61. 


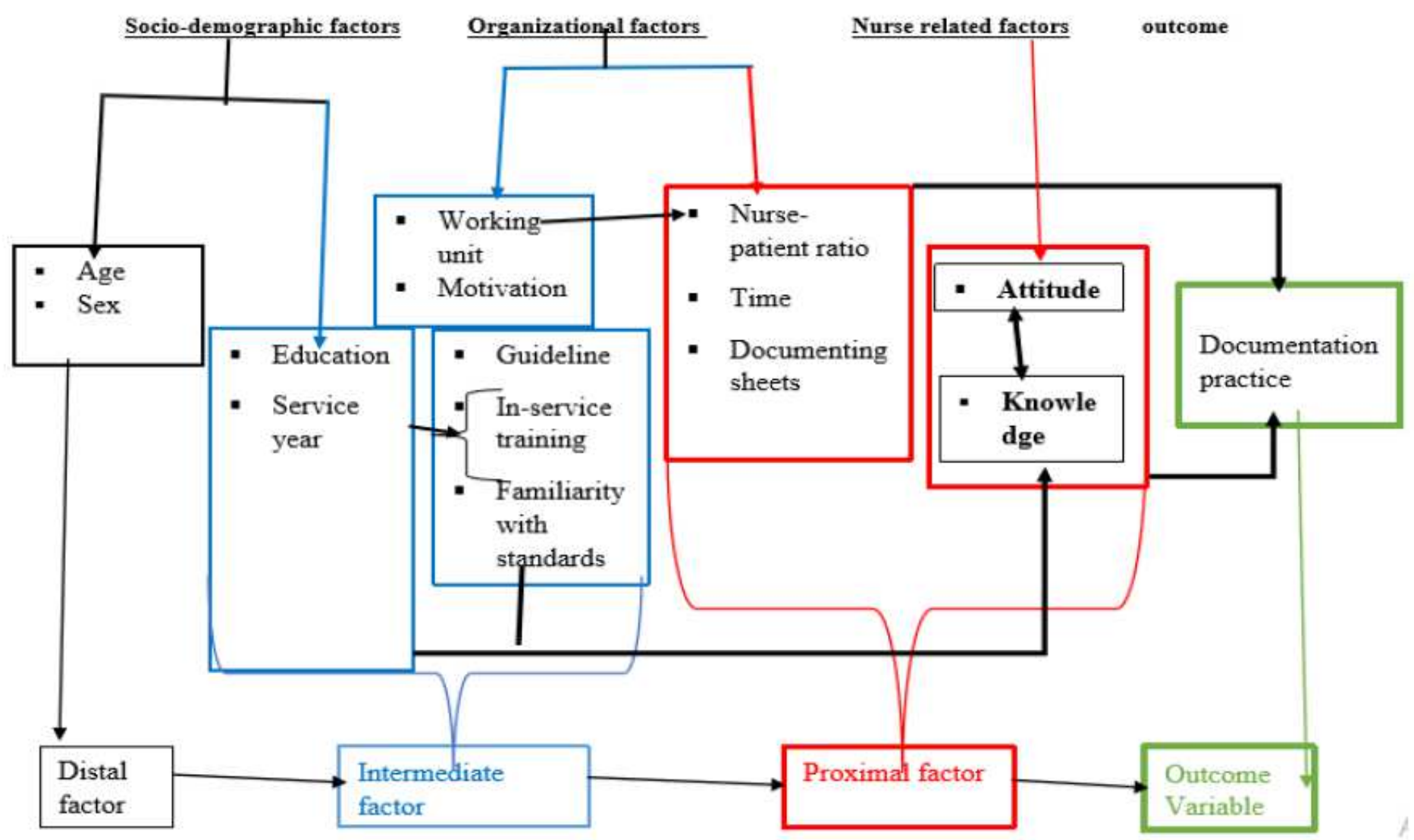

\section{Figure 1}

A conceptual framework of Documentation Practice and Associated Factors among Nurses in Harari Region and Dire Dawa Administration Governmental Hospitals, Eastern Ethiopia 2019 adopted and modified from (1).

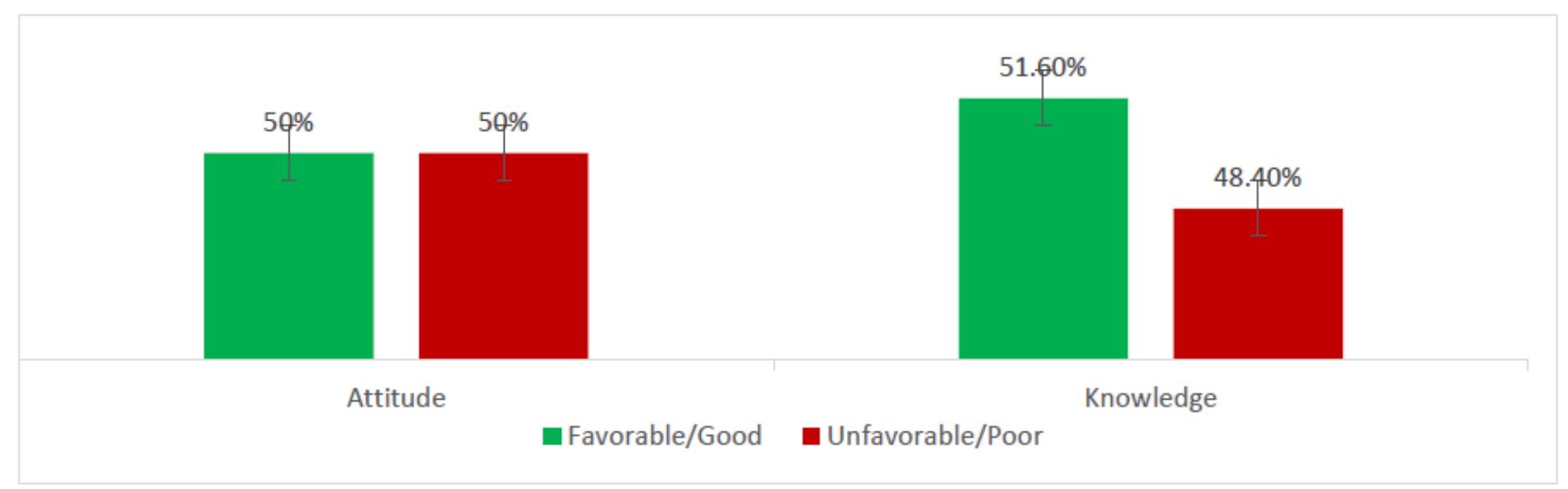

Figure 2 
Graphic representation of categorized Attitude and knowledge of nurses towards nursing documentation in Governmental Hospitals of Harari Regional State and Dire Dawa City Administration, Eastern Ethiopia, $2019(n=430)$.

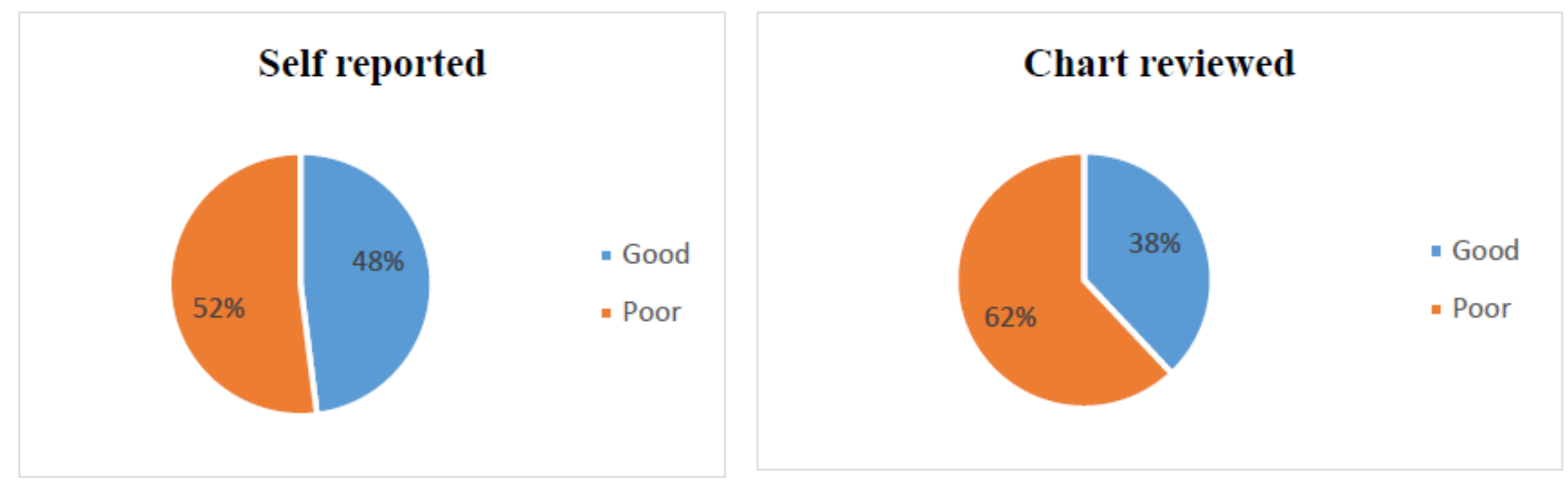

Figure 3

Categorized self-reported and chart reviewed documentation practices among nurses in Governmental Hospitals of Harari Regional State and Dire Dawa Administration, Eastern Ethiopia ( $n=430$ and $n=421$ respectively ). 